\title{
CRESCIMENTO BIOMÉTRICO DO AMENDOINZEIRO BR1 SOB SALINIDADE DA ÁGUA E COMPOSTO ORGÂNICO DE MAMONEIRA
}

\author{
Alian Cássio Pereira Cavalcante ${ }^{1}$; Adailza Guilherme Cavalcante ${ }^{2}$; Manoel Alexandre Diniz Neto \\ Lourival Ferreira Cavalcante ${ }^{4}$; Antônio Gustavo de Luna Souto ${ }^{5}$; Belísia Lúcia Moreira Toscano \\ $\operatorname{Diniz}^{6}$
}

'Doutorando em Fitotecnia, CCA/UFV, Viçosa, MG, cassio.alian21 @gmail.com; ²Doutoranda em Agronomia (Produção Vegetal), FCAV/UNESP, Jaboticabal, SP; ${ }^{3}$ Docente do CCHSA/UFPB, Bananeiras, PB; ${ }^{4}$ Docente do CCA/UFPB, Areia, PB; ${ }^{5}$ Doutor em Fitotecnia, CCA/UFV, Viçosa, MG; ${ }^{6}$ Docente do CCHSA/UFPB, Bananeiras, PB.

RESUMO: Objetivou-se avaliar o crescimento das plantas irrigadas com águas de salinidade crescente em substrato com composto de mamoneira em Bananeiras-PB. O delineamento experimental em blocos casualizados consistiu do arranjo fatorial $5 \times 2$, relativo aos níveis de água salina de 0,$5 ; 1,5$; 3,$0 ; 4,5$ e $6,0 \mathrm{dS} \mathrm{m}^{-1}$ e duas proporções em volume de composto de mamona + solo (0:1 e 1:1 v:v). Aos 90 dias após a semeadura avaliaram-se o crescimento em a altura, diâmetro da haste principal, número de ramos e de ginóforos, comprimento da raiz principal e índice de área foliar. A salinidade da água de irrigação comprometeu o crescimento biométrico do amendoinzeiro a partir da condutividade média de 3,1 e 1,8 dS m m $^{-1}$ nos substratos com e sem composto orgânico respectivamente; os resultados constatam que a adição do composto orgânico atenua o efeito salino nas plantas.

Palavras chave: Arachis hypogaea L., insumo orgânico, crescimento inicial

\section{INTRODUÇÃO}

O amendoim (Arachis hypogaea L.) é a sexta cultura oleaginosa mais importante do mundo com elevada importância econômica, para atender a indústria química e alimentícia (PAWAR et al., 2018). Dentre as oleaginosas, por ser rica em óleo, proteínas e vitaminas, é uma das mais conhecidas e consumidas por quase todos os povos (HIPPLER et al., 2011). Atualmente é a quarta oleaginosa mais cultivada do mundo, ocupando uma área de 23 milhões de hectares, com uma produção mundial de 36 milhões de toneladas anuais (FAO, 2016).

Algumas limitações ao cultivo do amendoinzeiro nas áreas semiáridas são as condições físicas dos solos e o teor salino das águas ação e/ou do solo não tolerado pela cultura devido diminuir o potencial osmótico da solução, reduzindo a disponibilidade de água e nutrientes às plantas (SOUZA et al., 2010). A sobrevivência das plantas sob condições salinas, em geral, exige processos adaptativos quanto à absorção, transporte e distribuição de íons nos vários órgãos das plantas (GARCIA et al., 2010). Essa condição, associada ao emprego de resíduos orgânicos, ricos em ácidos orgânicos pode 
16 e 17 de agosto de 2018, centro de convenções da FCAV/UNESP - Câmpus de Jaboticabal, SP

diminuir a ação dos efeitos danosos da salinidade da água e do solo às plantas (SILVA JÚNIOR et al., 2009; VOLIK et al., 2018).

A matéria orgânica quando fornecida ao solo ou substrato em dosagens balanceadas proporciona efeitos positivos no desenvolvimento das culturas devido a contribuição na disponibilidade de nutrientes e melhoria na microbiota do solo (TAKRITI et al., 2018). O aproveitamento agrícola de resíduos orgânicos na forma de composto orgânico pode resultar na sustentabilidade do agroecossistema por possibilitar a reciclagem de nutrientes e a redução da contaminação ambiental. Os adubos orgânicos são insumos com cores escuras, consistência friável, ricos em húmus, originados da ação fermentativa e digestiva de microrganismos em ambiente aeróbico no material vegetal (PRIMO et al., 2010).

Pesquisas por estratégias de manejo, que possibilitem a exploração de áreas irrigadas com água salina nas atividades agrícolas, constituem um desafio que vem sendo superado com o emprego de insumos orgânicos que reduzam a intensidade dos efeitos danosos dos sais, possibilitando o uso de águas salinas durante o crescimento das plantas (SOUZA et al., 2008; CAVALCANTE et al., 2016). Considerando a importância da cultura do amendoinzeiro, objetivou-se avaliar o crescimento das plantas submetidas à irrigação com águas de salinidade crescente no substrato com proporções de composto orgânico de restos vegetais da mamoneira.

\section{MATERIAL E METÓDOS}

O experimento foi conduzido em estufa telada, no período de fevereiro a maio de 2014, no Setor de Agricultura, Centro de Ciências Humanas, Sociais e Agrárias (CCHSA) da Universidade Federal da Paraíba, Bananeiras-PB, localizado na Microrregião do Brejo paraibano.

A compostagem foi feita em leira utilizando restos de plantas de mamoneira (Ricinus communis) e esterco bovino. Os tratamentos foram distribuídos em blocos casualizados usando o arranjo fatorial $5 \times 2$, constante dos níveis de água salina de 0,$5 ; 1,5 ; 3,0 ; 4,5$; e $6,0 \mathrm{dS} \mathrm{m}^{-1}$ e as proporções de composto de mamona (CM) + solo (S) nos substratos de 0:1 e 1:1 cujos resultados da análise química podem ser observados na (Tabela 1).

Tabela1. Caracterização química e de fertilidade do composto orgânico de mamoneira (CM) e do solo utilizados na constituição dos substratos.

\begin{tabular}{|c|c|c|c|c|c|c|c|c|c|c|c|c|}
\hline \multirow[b]{2}{*}{ Fontes } & \multicolumn{12}{|c|}{ Atributos Químicos } \\
\hline & $\mathrm{pH}$ & $\begin{array}{c}\mathrm{P} \\
\mathrm{mg} \mathrm{dm}^{-1}\end{array}$ & $\mathrm{~K}^{+}$ & $\mathrm{Na}^{+}$ & $\mathrm{H}^{+} \mathrm{Al}^{+3}$ & $\begin{array}{c}\mathrm{Al}^{+3} \\
-\mathrm{cmo}^{2}\end{array}$ & $\begin{array}{c}\mathrm{Ca}^{+2} \\
\mathrm{dm}^{-3}-\end{array}$ & $\mathrm{Mg}^{+2}$ & SB & CTC & $\begin{array}{l}\mathrm{V} \\
\%\end{array}$ & $\begin{array}{c}\mathrm{MO} \\
\mathrm{g} \mathrm{kg}^{-1}\end{array}$ \\
\hline Solo & 5,7 & 19,1 & 0,23 & 0,1 & 0,2 & 0,0 & 4,4 & 0,4 & 5,1 & 5,3 & 96,9 & 10,4 \\
\hline $\mathrm{CM}$ & 8,2 & 921,0 & 12,3 & 1,5 & 0,8 & 0,0 & 14,1 & 4,2 & - & - & - & 259 \\
\hline
\end{tabular}

O solo utilizado nas misturas composto orgânico foi coletado no município de Bananeiras-PB sendo um Latossolo Amarelo distrófico (EMBRAPA, 2013), mas devido às adubações de anos 
anteriores apresenta-se na camada superficial como eutrófico. As sementes de amendoim cultivar BR1 foram provenientes da EMBRAPA Algodão localizada na cidade de Campina Grande-PB. As unidades experimentais foram vasos plásticos com capacidade para $5 \mathrm{dm}^{-3}$ de substrato; quatro sementes por unidade experimental. As variáveis analisadas foram altura de planta medida do nível do solo ao ápice do meristema apical com uma régua graduada, diâmetro da haste principal obtido com paquímetro digital a $1 \mathrm{~cm}$ de altura do solo, contagem do ramos e dos ginóforos, comprimento de raiz principal com régua milimetrada na distância entre o colo e a extremidade da raiz, e índice de área foliar, com o equipamento AccuPAR LP-80. As médias referentes à presença e ausência de composto orgânico, comparadas pelo teste F, que neste caso é conclusivo e as médias da composição do substrato, comparadas por regressão. A análise estatística foi realizada pelo software estatístico Sisvar versão 5.6 (FERREIRA, 2014).

\section{RESULTADOS E DISCUSSÕES}

A altura de plantas de amendoim não respondeu aos efeitos da interação entre a salinidade da água e as proporções do composto orgânico (Figura 1A), a medida que aumentou a condutividade elétrica da água (CEa) houve uma redução em altura a partir de $2,3 \mathrm{dS} \mathrm{m}^{-1}$. Quando incorporado composto orgânico ao substrato os efeitos da salinidade foram atenuados proporcionando um incremento de $56,82 \%$ na altura da planta (Figura 1B).

SOUSA et al. (2012) observaram efeito semelhante para essa variável na cultura do amendoinzeiro com o aumento da $\mathrm{CEa}$, ressaltando ainda a importância de utilizar algum tipo de condicionante orgânico em ambiente salino. GRACIANO et al. (2011), afirmam que o decréscimo da altura da planta é resposta da redução do potencial osmótico da solução do solo devido ao incremento de sais.

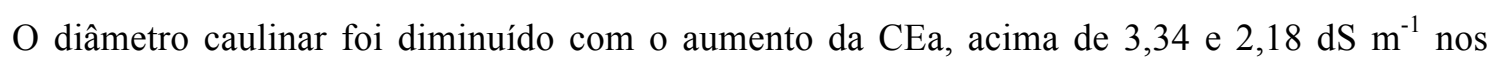
tratamentos som e sem composto orgânico respectivamente, porém com maior intensidade nas mudas sem a presença do composto orgânico (Figura 1C). GRACIANO et al. (2011) nessa mesma cultura observaram declínio semelhante em função da salinidade das águas no solo sem aplicação de biofertilizante. No substrato com composto orgânico percebe-se aumento no número de ramos por planta. As plantas sem a presença do composto orgânico provocou um decréscimo na água salina com $6 \mathrm{dS} \mathrm{m}{ }^{-1}$, provocando a morte das plantas nesse tratamento (Figura 1D). 

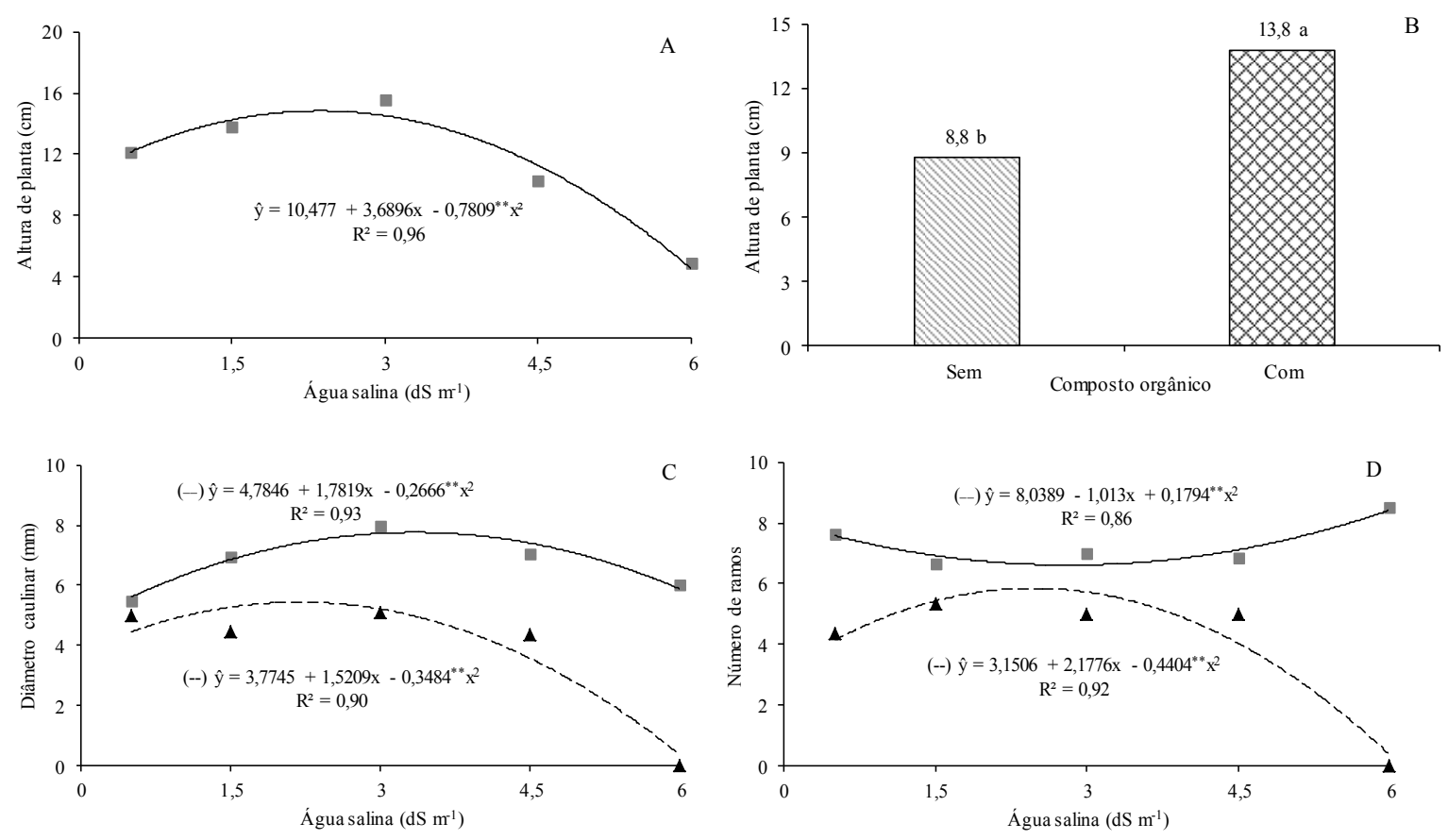

Figura 1- Altura de plantas (A e B), diâmetro caulinar (C) e número de ramos (D) em plantas de amendoinzeiro irrigadas com diferente condutividade elétrica na presença $(-)$ e ausência (--) de composto orgânico no substrato.

O maior incremento de ginóforos foi até a condutividade de $1,8 \mathrm{dS} \mathrm{m} \mathrm{m}^{-1}$ com valor de 12 ginóforos planta ${ }^{-1}$, entretanto o composto orgânico na proporção de $1: 1$, proporcionou incremento de 146,11\% comparado as plantas sem o insumo orgânico (Figura 2A e B). Segundo VOLIKET et al. (2018) a matéria orgânica funciona com condicionador na atenuação do efeito deletério da salinidade, proporcionando melhor condições para o desenvolvimento das plantas.

Para o comprimento radicular e o índice de área foliar (Figura $2 \mathrm{C}$ e D) as plantas de amendoinzeiro responderam de forma semelhante com diminuição a partir da concentração de 3,37; 2,49 e 1,75; 1,81 dS m${ }^{-1}$ respectivamente, o que segundo MEENA et al. (2016) a salinidade proporciona diminuição no desenvolvimento estrutural da raiz. Entretanto os substratos com composto orgânico atenua o efeito salino no comprimento radicular e área foliar, simultaneamente.

Em ambas as variáveis o composto orgânico proporcionou a redução dos efeitos danosos dos sais presentes na água de irrigação às plantas. Segundo CAVALCANTE et al. (2010), o efeito positivo dos materiais orgânicos está na liberação de substâncias húmicas em solos salinos. CAVALCANTE et al. (2016) ao avaliarem a interação entre salinidade e matéria orgânica no substrato observaram maior área foliar em mudas de oiticica (Licania rigida) cultivadas com o respectivo insumo. 

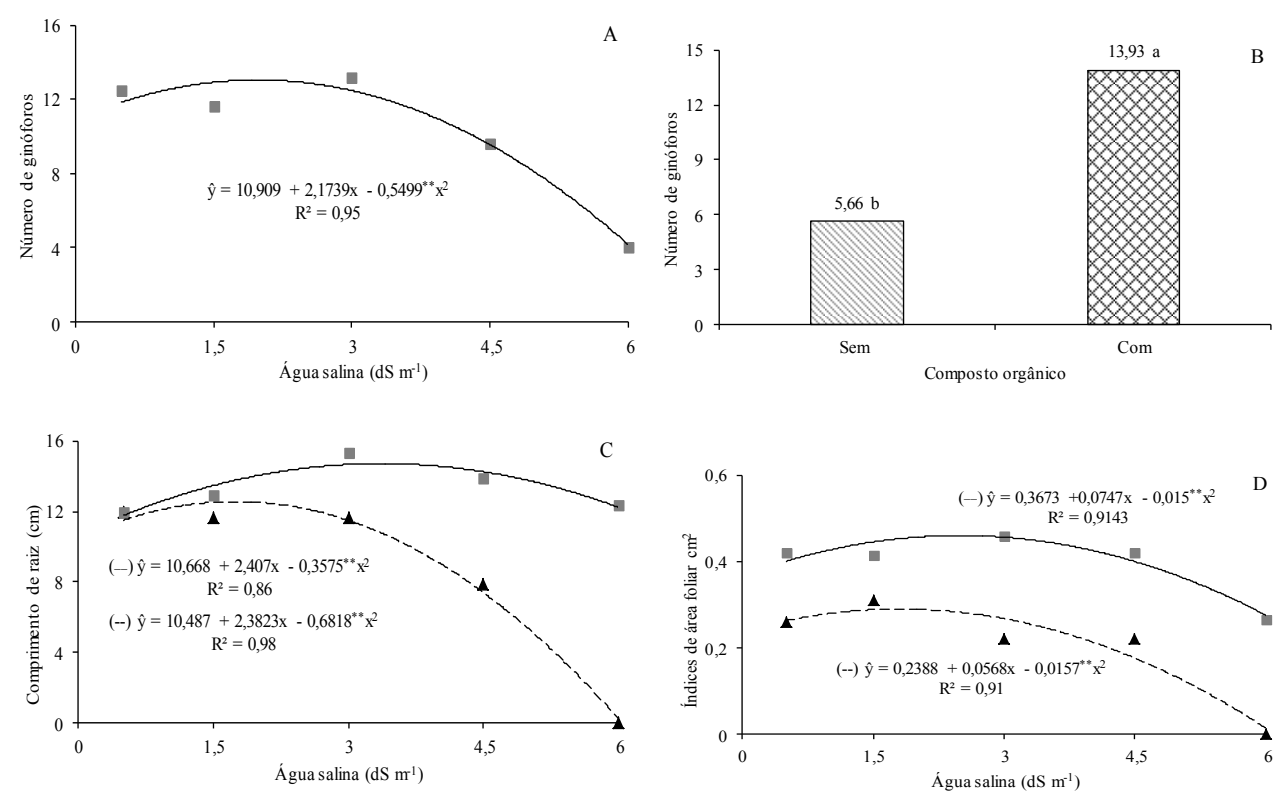

Figura 2- Número de ginóforos (A e B), comprimento radicular (C) e índice de área foliar (D) em plantas de amendoinzeiro irrigadas com diferente condutividade elétrica na presença (-) e ausência (-) de composto orgânico no substrato.

\section{CONCLUSÃO}

A condutividade elétrica da água de irrigação diminui o crescimento do amendoinzeiro a partir da condutividade média de 3,1 e $1,8 \mathrm{dS} \mathrm{m}^{-1}$ nos substratos com e sem composto orgânico respectivamente, mas a adição do composto orgânico atenua o efeito estressante dos sais às plantas.

\section{REFERÊNCIAS BIBLIOGRAFICAS}

CAVALCANTE, L. F.; VIEIRA, M. S.; SANTOS, A. F.; OLIVEIRA, W. M.; NASCIMENTO, J. A. M. Água salina e esterco bovino líquido na formação de mudas de goiabeira cultivar paluma. Revista Brasileira de Fruticultura, v.32, n.1, p.251-261, 2010.

CAValcante, A. C. P.; Diniz Neto, M. A.; CAVAlCANTE, L. F.; CAVAlCANTE, A. G.; DINIZ, B. L. M. T. ARAÚJO, R. C.; MESQUITA E. F.; ZUZA, J. F. C. Saline water and organic matter in the development and quality of Licania rigida Benth seedlings. African Journal of Agricultural Research, v. 11, n. 30, p. 2796-2805, 2016.

EMBRAPA. Centro Nacional de Pesquisa de Solos. Sistema Brasileiro de Classificação de Solos. 3. ed. Brasília, DF: Embrapa Solos, 2013. 353 p.

FAO - FOOD AGRICULTURE ORGANIZATION OF UNITED NATIONS. Statistics at FAO. Disponível em: <http://www.fao.org/corp/statistics/> Acesso em 02/05/2018.

FERREIRA, D. F. Sisvar: a Guide for its Bootstrap procedures in multiple comparisons. Ciência e Agrotecnologia, v. 38, n. 2, p. 109-112, 2014.

GARCIA, G. O.; NAZÁRIO, A. A.; MORAES, W. B.; GONÇALVES, I. Z.; MADALÃO, J. C. Respostas de genótipos de feijoeiro á salinidade. Engenharia na Agricultura, v.18, p. 330-338, 2010. 
GRACIANO, E. S. A.; NOGUEIRA, R. J. M. C.; LIMA, D. R. M.; PACHECO, C. M.; SANTOS, R. C. Crescimento e capacidade fotossintética da cultivar de amendoim BR 1 sob condições de salinidade. Revista Brasileira de Engenharia Agrícola e Ambiental, v.15, n. 8, p. 794-800, 2011.

HIPPlER, F. W. R.; MOREIRA, M.; DIAS, N. M. S.; HERMANN, E. R. Fungos micorrízicosarbusculares nativos e doses de fósforo no desenvolvimento do amendoim RUNNER IAC 886. Revista Ciência Agronômica, v. 42, n. 3, p. 605-610, 2011.

MEENA, H. N.; MEENA, M.; YADAV R. S. Comparative performance of seed types on yield potential of peanut (Arachis hypogaea L.) under saline irrigation. Field Crops Research, v. 196, p. 305-310, 2016.

PAWAR, P. B.; KHADILKAR, J. P.; KULKARNI, M. V.; MELO J. S.An approach to enhance nutritive quality of groundnut (Arachis hypogaea L.) seed oil through endomycorrhizalfertigation. Biocatalysis and Agricultural Biotechnology, v. 14, p. 18-22, 2018.

PRIMO, D. C.; FADIGAS, F. S.; CARVALHO, J. C. R.; SCHMIDT, C. D. S.; BORGES FILHO, A. C. S. Avaliação da qualidade nutricional de composto orgânico produzido com resíduos de fumo. Revista Brasileira de Engenharia Agrícola e Ambiental, v. 14, n. 7, p. 742-746, 2010.

SILVA JÚNIOR, J. M. T.; TAVARES, R. C.; MENDES FILHO, P. F.; GOMES, V. F. F. Efeitos de níveis de salinidade sobre a atividade microbiana de um Argissolo Amarelo incubado com diferentes adubos orgânicos. Revista Brasileira de Ciências Agrárias, v.4, p.378-382, 2009.

SOUZA, G. B.; CAVALCANTE, L. F.; CAVALCANTE, I. H. L.; BECKMANN-CAVALCANTE, M. Z. Salinidade do substrato contendo biofertilizante para formação de mudas de maracujazeiro irrigado com água salina. Revista Caatinga, 21, n. 2, p. 172-180, 2008.

SOUSA, G. G.; LACERDA, C. F.; CAVALCANTE, L. F.; GUIMARÃES, F. V.A.; BEZERRA, M. E. J.; SILVA, G. L. Nutrição mineral e extração de nutrientes de planta de milho irrigada com água salina. Revista Brasileira de Engenharia Agrícola e Ambiental, v.14, n. 11, p.1143-1151, 2010.

SOUSA, G. G.; AZEVEDO, B. M.; ALBUQUERQUE, A. H. P.; MESQUiTA, J. B. R.; VIANA, T. V. A. Características agronômicas do amendoinzeiro sob irrigação com águas salinas em solo com biofertilizantes. Revista Agro@mbiente, v. 6, n. 2, p. 124-132, 2012.

TAKRITI, M.; WILD, B.; SCHNECKER, J.; MOOSHAMMER, M.; KNOLTSCH, A.; LASHCHINSKIY, N.; ELOY, A. R. J.; GENTSCH, N.; MIKUTTA, A. G. R.; WANEK, W.; RICHTER, A. Soil organic matter quality exerts a stronger control than stoichiometry on microbial substrate use efficiency along a latitudinal transect. Soil Biology \& Biochemistry, v. 121, p. 212-220, 2018.

VOLIK, O.; PETRONE, R. M.; HALl, R. I.; MACRAE, M. L.; Wells, C. M.; PRICE, J. S. Organic matter accumulation and salinity change in open water areas within a saline boreal fen in the Athabasca Oil Sands Region, Canada. Catena, v. 165, p. 425-433, 2018. 